\title{
Cyclic Loading Test of a Bamboo-steel Hybrid Frame with Novel Energy-dissipation Connections
}

\author{
Yanhua Wang ${ }^{\mathrm{a}, \mathrm{b}, *}$, Yan Feng ${ }^{\mathrm{a}, \mathrm{b}}$, Zirui Huang ${ }^{\mathrm{a}, \mathrm{b}}$, Zhongfan Chen ${ }^{\mathrm{a}, \mathrm{b}}$ \\ Pseudo-static tests of a novel energy-dissipation connection, comprised \\ of a hinge and two steel brackets, have proven their reliability and superior \\ energy-dissipation capability. To verify the effectiveness of the connection \\ further, a full-scale one-story one-bay engineered bamboo-steel hybrid \\ frame jointed with the novel energy-dissipation connections was \\ investigated through experimental test and finite element analysis (FEA) \\ in this paper. The experimental results showed that the failure mode of the \\ frame was restricted in the local buckling of the energy-dissipation panels \\ (EDPs) in the innovative connections, whereas no obvious damage was \\ observed in the other components of the frame. The hysteresis loops of \\ the frame with energy dissipation connections revealed less pinching. \\ Thus, the ductility and damping ratio of the engineered bamboo-steel \\ frame can reach 1.46 and $14.1 \%$, respectively. Based on the analysis of \\ effectual simulation models in ABAQUS software, the relationship \\ between the initial stiffness, the peak load, the ductility ratio of the hybrid \\ frame and the size of EDP was studied. Recommendations are made for \\ the design of the EDPs.
}

Keywords: Engineered bamboo-steel hybrid frame; Energy dissipation connections; Cyclic behavior; Finite element simulation

Contact information: a: Key Laboratory of RC\&PC Structures of Ministry of Education, Southeast University, Nanjing, 210096 China; b: School of Civil Engineering, Southeast University, Nanjing, 211189 China; *Corresponding author: wyh00737@ seu.edu.cn

\section{INTRODUCTION}

In recent decades, engineered bamboo products have demonstrated their superior advantages in relieving the severe pressure that traditional building materials have brought. As an eco-friendly, renewable and reliable alternative of conventional building material, they have achieved great success in low-rise buildings (Porteous and Kermani 2013; Karacabeyli and Lum 2014; Williams and Karacabey 2014; Adi et al. 2015).

However, the demand of the real-estate market is still focused on high-rise buildings, since China does not have enough land supply to support the low-rise buildings for large populations. And the inherent limits of engineered bamboo products when used as perpendicular bearing components, i.e., the accumulated creep and requirement for a larger size, give rise to a great restriction on bamboo products in the application of highrise buildings (Van der Lugt et al. 2006; Huang et al. 2013; Huang et al. 2015; Hurmekoski et al. 2015).

Ways to fully display the advantages of engineered bamboo and to solve the problems above have been explored. Studies on multistory timber and engineered bamboo structures have mainly focused on novel structural systems, such as pre-stressed timber structures (Buchanan et al. 2008; Shiratori et al. 2009; Sharma et al. 2015; Huang et al. 2016), steel- timber or engineered bamboo based hybrid frames and shear walls (Sakamoto 
et al. 2004; He et al. 2013; Li et al. 2016), as well as new connections utilized for these novel structures (Xiong et al. 2016; Schober and Tannert 2016; Loss et al. 2016; Li et al. 2018). Seismic performance assessments based on cyclic loading or pushover tests were conducted and suggestions on the designs were proposed. Among them, an engineered bamboo-steel hybrid structure provides a practical solution to extend engineered bamboo products for multi- and high-rise building constructions. By using steel as vertical components and engineered bamboo products as horizontal components, the limitation of the engineered bamboo used in multi- and high-rise buildings can be overcome. Obviously, the seismic performance of connection used for the frame is the major concern to make the structure work effectively.

Generally, the ideal conception of the frame is to control the damage and failure of the components in the desired modes, and to make the frame have enough initial stiffness to meet the serviceability requirement as well as good ductility to consume the seismic energy input. Typically, there are two types of connections available, i.e., dowel-type and bolt-type connections, for wood or engineered bamboo structures (Quenneville and Mohammad 2001; Mohammad and Quenneville 2001; Kharouf et al. 2003; Bouchaïr et al. 2007; Araki et al. 2011). The performances of these connections, however, cannot be well controlled because of the complicated damage mechanism (Santos et al. 2013).

A novel energy-dissipation connection is proposed by Huang et al. (2019), which incorporates a hinge and a pair of top- seat brackets to carry shear force and moment from the connecting beam, respectively. The detail of the connection is illustrated in Fig. 1, and it can be seen that each bracket consists of two segments, i.e. the joint panel and the energy dissipation panel (EDP). The joint panel is welded to a steel stub bolted to two sandwich beam panels, while the EDP is welded to a base panel through which the connection is fixed to the steel column. And the EDPs are free of out-of-plane restrictions so that they can deform freely perpendicular to its own plane. In this way, the connection behaves as a seesaw supported on the hinge, which bears most of the shearing force at the end of connected beam. The top and seat brackets restrict the rotation of the connection, providing resistant moment and lateral stiffness for the frame, as shown in Fig. 1. The cyclic loading tests found that by a proper design, the damage of the frame could be restricted to the EDP, while the other parts of the connection, the beams and the columns of the frame, could be free of damage. The hysteresis loops of the connections exhibited limited pinching and provided a high damping ratio, indicating that the connection had good energy dissipation capability. The ductility ratio and damping ratio of the 9 connection tests all reached more than 3.0 and $30 \%$, respectively, showing reliability of the energy-dissipation connection.

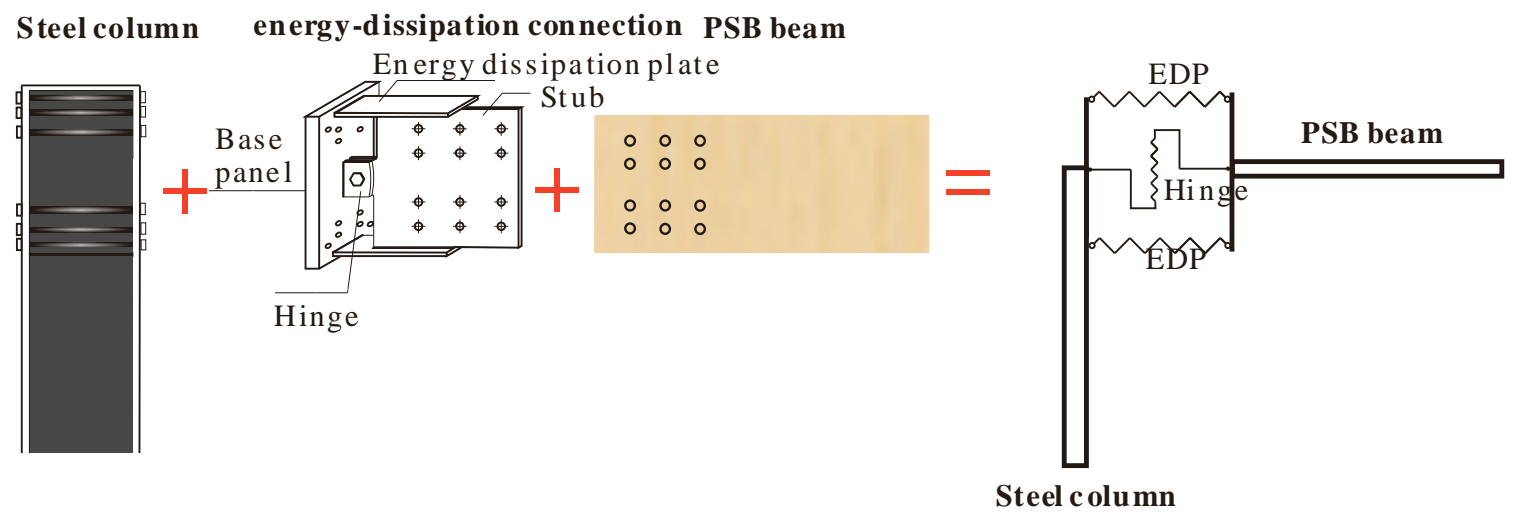

Fig. 1. Details of moment connection for engineered bamboo-steel moment hybrid frame 
To study the energy-dissipation connection further and verify its effectiveness, a full-scale one-story one-bay engineered bamboo-steel hybrid frame jointed with two energy-dissipation connections was tested and analyzed. The objective was to investigate the seismic performances of the hybrid frame and reliability of the connections. The seismic performance refers to failure pattern, failure mechanism, hysteresis loops, ductility ratio, and energy dissipation capacity. The design principle to ensure that the energy dissipation connections can fully display their energy-dissipation capacity were proposed. It should be noted that the tested hybrid frame is a structure before the wall material has been installed, which does not include the effects of a "wall" or other components that might serve the role of a brace to prevent deviations from 90-degree angles of the frame. Moreover, the effects of walls or other reinforcement methods is the study aim of the next stage of research.

\section{EXPERIMENTAL INVESTIGATION}

According to the design principles in reference (Huang et al. 2019), the frame connected with EDPs was designed to avoid failure on beams, columns, and bolt-joints, which have less ductility and uncontrolled stiffness and strength. The stiffness and strength of the structure can be controlled as expected and the failure of the frame can be restricted in EDPs, which may provide good ductility and additional damp for the structure. Thus, a full-size engineered bamboo-steel hybrid frame with EDP connections was employed to conduct cyclic loading test. The failure mode, hysteresis performance, and energy dissipation ability of the frame were studied.

\section{Specimen Preparation}

The dimensions of test frames are presented in Fig. 2.

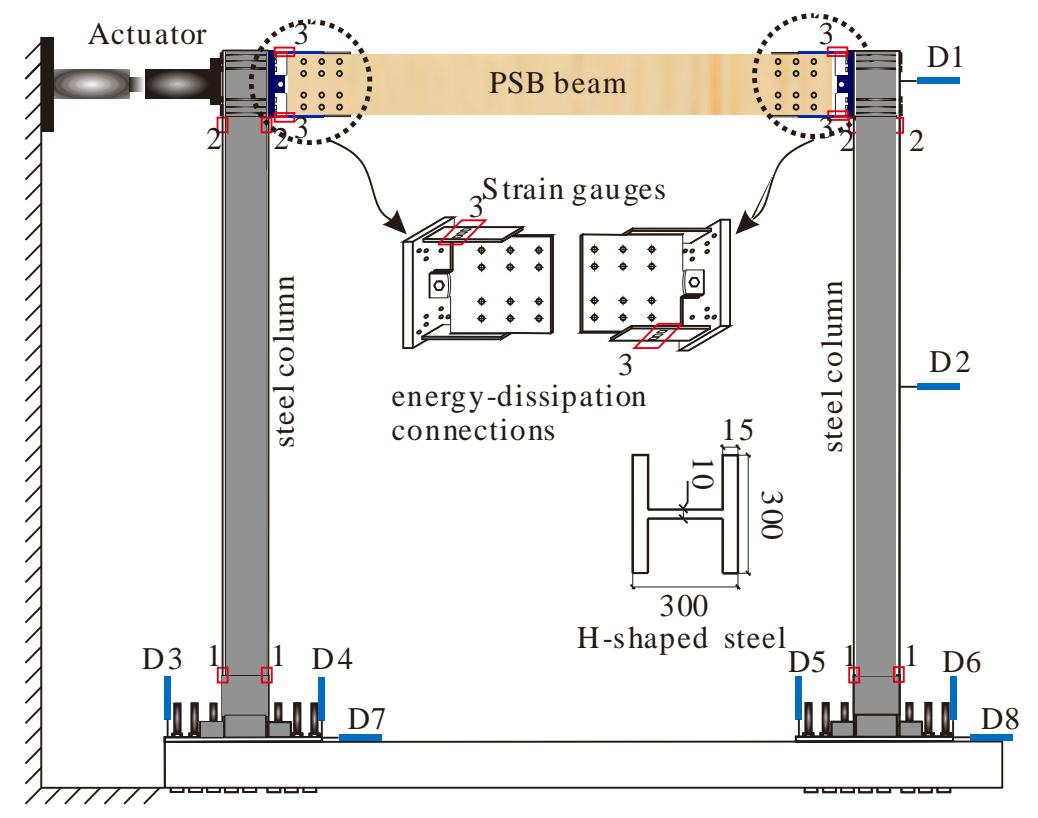

Fig. 2. Details of the frame and connection 
H-shaped steel with dimension of $300 \mathrm{~mm} \times 300 \mathrm{~mm} \times 10 \mathrm{~mm} \times 15 \mathrm{~mm}$ was employed as frame columns. Two PSB panels with same cross-section of $400 \mathrm{~mm} \times 120$ $\mathrm{mm}$ were selected as the frame beam. The base panel of the connection was mounted on the column through 12 bolts of $20 \mathrm{~mm}$ dimeters. The PSB panels were mounted on the two sides of steel stub of the connection, respectively, through 12 bolts of $22 \mathrm{~mm}$ in dimeters. Figure 2 schematically illustrates the joint manner in detail. The thickness of the EDPs is $5 \mathrm{~mm}$, and detailed sizes of the connection can be obtained from Huang et al. (2019). The strengths of all bolt joints were pre-checked to avoid joint premature failure before EDP yield. In this way, the column, beam, and the energy-dissipation connection were rigidly jointed. The bolts between the laboratory floor and the column were designed with large redundancy and tightened continuously during the test, so the connections there could be also seen as rigid.

There was no vertical load exerted on the frame. The reasons can be explained as follows: it is the moment-resistance capacity of the energy-dissipation joint that directly relates to the seismic performance of the hybrid frame. The vertical load is exerted on the columns, which has no actual influence on the study of the moment connections.

The steel of columns and connection were all Q-235, according to China standard GB 50017-2017 (2017). The steel of columns and connection are all Q-235 grade. Mechanical properties of the steel and PSB were tested before experiment, which are collected in Table 1.

Table 1. Mechanical Properties of Steel and PSB

\begin{tabular}{|c|c|c|c|c|c|}
\hline Materials & $\begin{array}{c}\text { Yield } \\
\text { strength/MPa }\end{array}$ & $\begin{array}{c}\text { Ultimate } \\
\text { strength/MPa }\end{array}$ & $\begin{array}{c}\text { Young's } \\
\text { modulus/GPa }\end{array}$ & $\begin{array}{c}\text { Poisson's } \\
\text { ratio }\end{array}$ & $\begin{array}{c}\text { Ratio of } \\
\text { elongation }\end{array}$ \\
\hline EDP & 315.25 & 443.03 & 209 & 0.28 & 0.41 \\
\hline Column & 272.55 & 438.73 & 217 & 0.28 & 0.32 \\
\hline PSB & - & - & 8.26 & - & - \\
\hline Bolt & 400 & - & 209 & 0.28 & - \\
\hline
\end{tabular}

In order to check the strength of bolted joints, the maximum moment-bearing of the EDP connection was estimated. In the previous study conducted by Huang et al. (2019), the maximum moment-bearing of EDP connection can be estimated by,

$$
M_{u}=\eta f_{\mathrm{u}} b t(h+t)
$$

where $f_{\mathrm{u}}(\mathrm{MPa})$ is the ultimate strength of the EDP steel; $b(\mathrm{~mm})$ and $t(\mathrm{~mm})$ are the width and thickness of the EDP, respectively; $h(\mathrm{~mm})$ is the clear space between the two EDPs; and $\eta$ is the coefficient that represents the degree of partial yielding which depends on the EDP length-to-thickness ratio and can be calculated by,

$$
\eta= \begin{cases}0.978 & 6.6 \leq \lambda \leq 7.2 \\ 0.749+1.150 e^{-\frac{\lambda}{1.897}} & 7.2<\lambda \leq 16.0\end{cases}
$$

where, $\lambda=l / t$, represents the length-to-thickness ratio of EDP, and $l(\mathrm{~mm})$ is the length of EDP. The check of the strength of bolts joints are presented in Table 2. The calculation can be explained as follows:

According to China standard GB 50005-2017 (2017) and GB 50017-2017(2017), the bolts between the beam and energy-dissipation connection bear the shear force by the bending moment and vertical force of the beam. While the bolts between the columns and 
energy-dissipation connection work under the pulling force caused by the bending moment and shear force transmitted by the end of the beam.

Table 2. Check of the Strength of Connections

\begin{tabular}{|c|c|c|}
\hline $\begin{array}{l}\text { Position of } \\
\text { the bolts }\end{array}$ & Calculation and check of the bolts & Notes \\
\hline \multirow[t]{2}{*}{$\begin{array}{l}\text { Beam \& } \\
\text { connection }\end{array}$} & $\begin{aligned} M & =M_{u}=\eta f_{\mathrm{u}} b t(h+t) \\
& =\left(0.749+1.150 e^{-\frac{80}{5 \times 1.897}}\right) \times 443.03 \times 100 \times 5 \times(400+5)=67.20 \mathrm{kN} \cdot \mathrm{m} \\
V & =\frac{2 M}{L}=\frac{2 \times 74.77}{3.31}=45.18 \mathrm{kN} \\
V & =V^{2}+\frac{M x_{\max }}{\left(\frac{M y_{\max }}{V^{2}}\right)^{2}}\end{aligned}$ & \multirow{2}{*}{$\begin{array}{l}\text { M--design moment } \\
\mathrm{V} \text {--design shear } \\
\mathrm{L}-\text {-length of the } \\
\text { beam } \\
V_{\max }-- \text { maximum } \\
\text { shear under the } \\
\text { mutual action of } \mathrm{M} \\
\text { and } \mathrm{V} \\
X_{\max } \text { and } \mathrm{y}_{\max }-- \\
\text { the maximum } \\
\text { displacement } \\
\text { between the bolt } \\
\text { and the rotation } \\
\text { center. }\end{array}$} \\
\hline & $\begin{array}{l}=\sqrt{\left(\frac{45.18}{12}+\frac{74770 \times 120}{6 \times\left(140^{2}+70^{2}\right)+8 \times 120^{2}}\right)^{2}+\left(\frac{74770 \times 140}{6 \times\left(140^{2}+70^{2}\right)+8 \times 120^{2}}\right)} \\
=34.52 \mathrm{kN} \leq N_{\min }^{b 1}\end{array}$ & \\
\hline \multirow[t]{2}{*}{$\begin{array}{l}\text { Column \& } \\
\text { connection }\end{array}$} & $\begin{array}{l}V_{\max }=\frac{V}{12}=\frac{45.18}{12}=3.77 \mathrm{kN} \leq N_{c}^{b} \\
T_{\max }=\frac{M y_{\max }}{\sum_{i=1}^{12} y_{\max }^{2}}=\frac{74.77 \times 450}{2 \times\left(450^{2}+390^{2}+320^{2}+130^{2}+60^{2}\right)} \times 10^{3}=31.66 \mathrm{kN} \\
\sqrt{\left(\frac{V_{\max }^{\prime}}{N_{\min }^{b 2}}\right)^{2}+\left(\frac{T_{\max } N^{b}}{N_{t}^{b}}\right)^{2}}=\sqrt{\left(\frac{3.77}{121.64}\right)^{2}+\left(\frac{35.23}{121.36}\right)^{2}}=0.26 \leq 1\end{array}$ & $\begin{array}{l}\text { The bolts in the } \\
\text { column and joint } \\
\text { are subjected to the } \\
\text { action of shear } \\
\text { distributed by } \mathrm{V} \text { and } \\
\text { tension distributed } \\
\text { by M. }\end{array}$ \\
\hline & $\begin{array}{l}N_{\min }^{b 1}=\min \left\{N_{v}^{b}, N_{c}^{b}\right\}=\min \left\{n_{v} \frac{\pi d^{2}}{4} f_{v}^{b}, d \sum t f_{c}^{b}\right\}=\min \left\{2 \times \frac{\pi \times 20^{2}}{4} \times 320,2\right. \\
N_{\min }^{b 2}=\min \left\{N_{v}^{b}, N_{c}^{b}\right\}=\min \left\{n_{v} \frac{\pi d^{2}}{4} f_{v}^{b}, d \sum t f_{c}^{b}\right\}=\min \left\{\frac{\pi \times 22^{2}}{4} \times 320,22 \times\right. \\
N_{t}^{b}=\frac{\pi d_{e}^{2}}{4} f_{t}^{b}=303.4 \times 400=121.36 \mathrm{kN} \\
d-\text { diameter of the bolt } \\
n_{v} \text {-number of the shear plane } \\
f_{v}^{b} \text {--design value of the shear strength of the bolt } \\
f_{c}^{b} \text {--design value of the compressive strength of the bolt } \\
f_{t}^{b} \text {--design value of the tensile strength of the bolt } \\
N_{\min }^{b 1} \text {--shear capacity of the bolts in beam \& connections } \\
N_{\min }^{b 2} \text {--shear capacity of the bolts in column \& connections } \\
N_{t}^{b} \text {--tensile capacity of the bolts in column \& connections }\end{array}$ & $\begin{array}{l}\times 12 \times 405\}=97.2 \mathrm{kN} \\
0 \times 405\}=121.64 \mathrm{kN}\end{array}$ \\
\hline
\end{tabular}

\section{Test Procedure}

Testing was performed in the Laboratory of Civil Engineering of Nanjing Forestry University. Horizontal cyclic loads were applied to the test specimen by a $1000-\mathrm{kN}$ hydraulic-servo actuator (Popwill, Hangzhou, China) with a displacement range of \pm 250 $\mathrm{mm}$. The actuator was jointed to the frame through a joint panel, which was fixed on the top of frame column by 4 bolts. The feet of steel columns were fixed on the rigid ground of the laboratory through 6 bolts. To prevent out-of-plane distortion and ensure the 
specimen deformed in the direction of applied load, a transverse support system was built at the two sides of the frame.

Eight linear variable differential transducers were used for displacement measurements of the specimen. To determine the strain variations in the EDPs, the strain gauges were arranged on the EDPs. All the linear variable differential transducers and strain gauges were connected to a data logger for automatic data acquisition during the testing.

The load regime contains two steps, as presented in Fig. 3: (1) preloading was conducted to check if all the bolt-joints were properly mounted and worked well. Then unloaded the actuator to zero and reset the acquisition system. (2) the next level load was controlled by the movement of actuator at the speed of $4 \mathrm{~mm} / \mathrm{min}$ before EDP yielding, while changed to $0.2 \Delta \mathrm{mm} / \mathrm{min}$ after the first yielding of the EDP took place, where, $\Delta$ represents the top displacement of first yielding of the frame. Three loading-unloading cycles were carried out for each loading grade after first yielding took place.

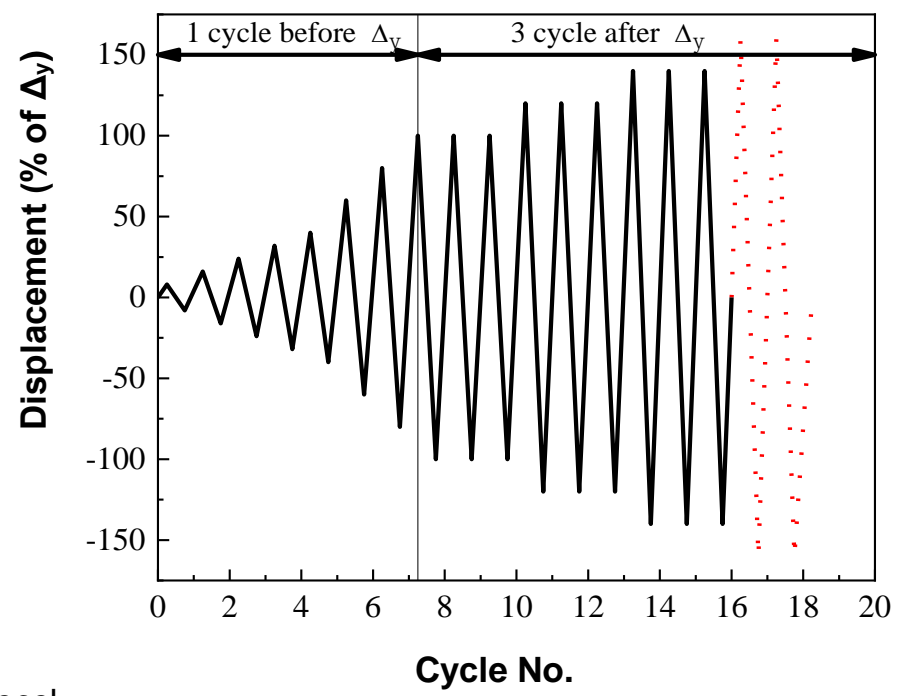

Fig. 3. Loading protocol

\section{Test Results}

Observations from experiment

Before the application of loading, 2 to $3 \mathrm{~mm}$ preloading had been applied to ensure that all components of the hybrid frame were well mounted. At the initial loading, there was no noise or distinct sliding occurring between the connections of other components. When the lateral displacement reached about $10 \mathrm{~mm}$ (command displacement of the actuator) and the corresponding external load was $36.1 \mathrm{kN}$, one strain gage at the middle of lower right EDP yielded first. Then the successive yielding of strain gages at other monitoring position in Fig. 4 can be observed with the augment of lateral load. When the lateral displacement at the top of the frame (measured by D1) reached $25 \mathrm{~mm}$, the strains of all the monitored positions exceeded the proportional limit and the lower right EDP in Fig. 2 yielded. Pronounced deformation of the EDP can be observed and the global loaddisplacement profile of the frame reached its summit point. At this moment, the external load applied on the frame was $100 \mathrm{kN}$. 


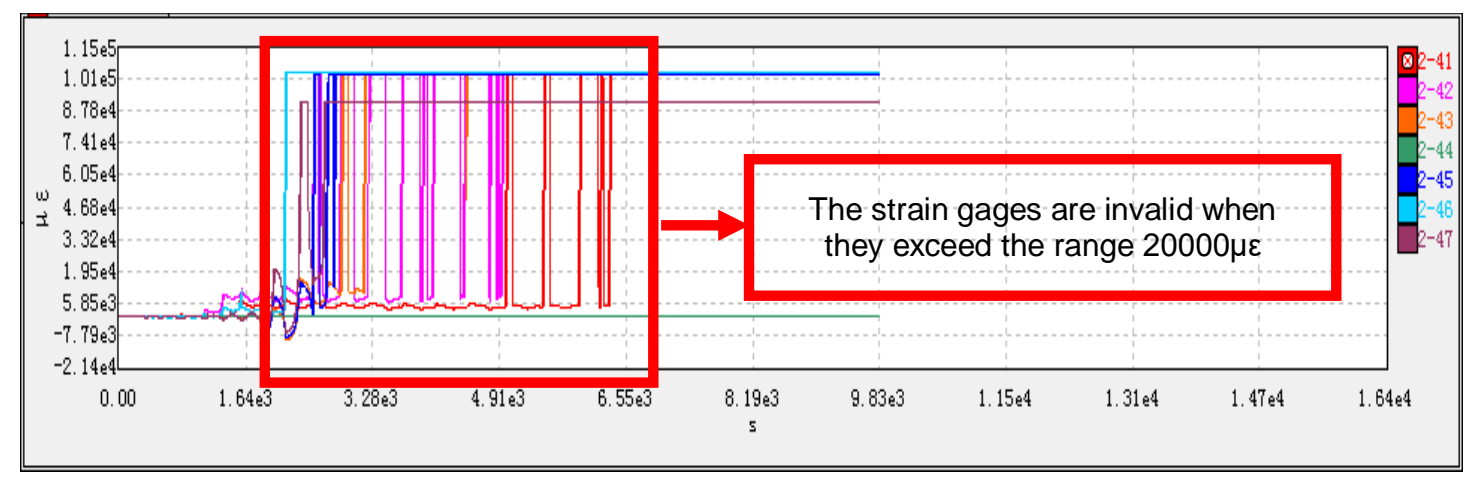

Fig. 4. Result of monitored strain gages at the EDPs (time vs. strain)

With the horizontal displacement increased further, the deformation of EDPs increased until the lateral displacement reached $30 \mathrm{~mm}$, and the middle of the lower EDP at the far-end of the actuator cracked. And when the lateral displacement reached $35 \mathrm{~mm}$, the middle of the other EDP at the close-end of the actuator cracked. Finally, the semi-rigid connections lost their load-carrying capacity. The failure mode is graphically illustrated in Fig. 5.

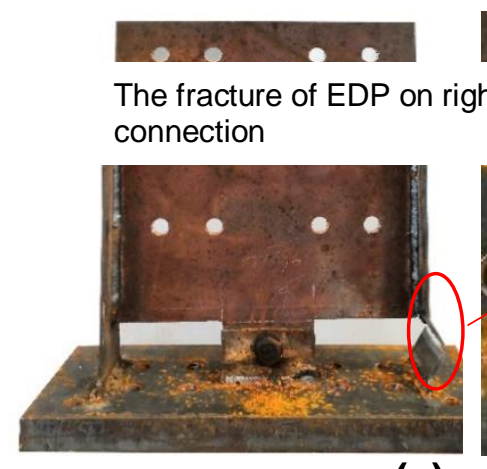

(a)

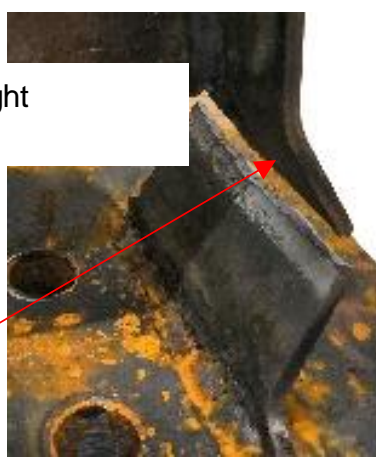

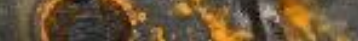
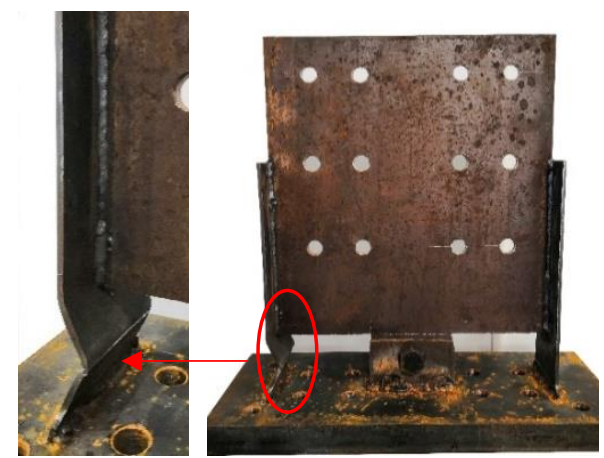

(b)

Fig. 5. Failure mode; (a) failure of the left connection; (b) failure of the right connection

It is worth noting that during the test, the steel columns both worked in elastic range. The elastic limits of the EDPs can be calculated from Table 1, which equals to $1508 \mu \varepsilon$. As shown in Fig. 6 the maximum strain of the monitored positions of the steel column reached about $500 \mu \varepsilon$.

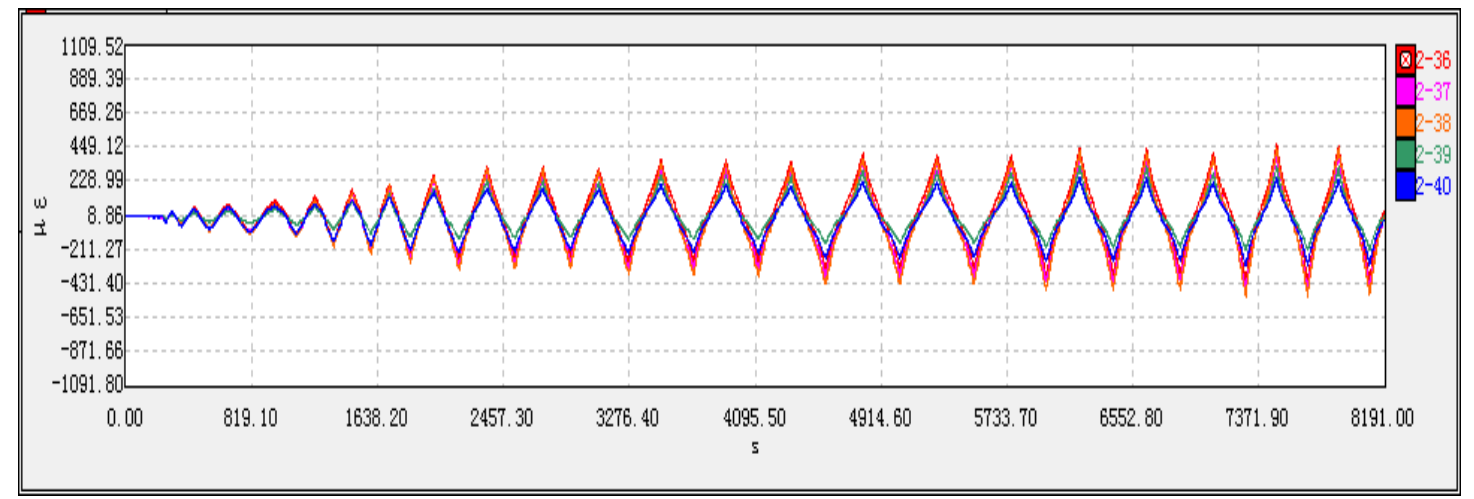

Fig. 6. Result of monitored maximum strain gages at the columns (time vs. strain) 
Figure 7 presents the status of other components after the cyclic loading test, and no significant distortion can be observed. It was as expected that the damage and failure were restricted in the energy dissipation panels (EDPs). And the other parts of the hybrid frame remained in their elastic working stages, which can serve as another fortification when the frame is stressed by a stronger earthquake or lateral force.

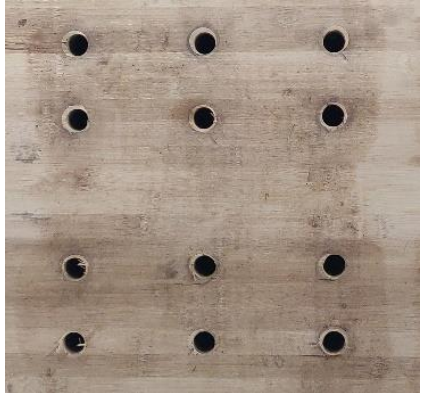

(a)

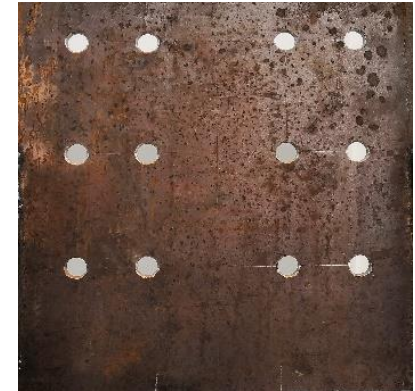

(b)

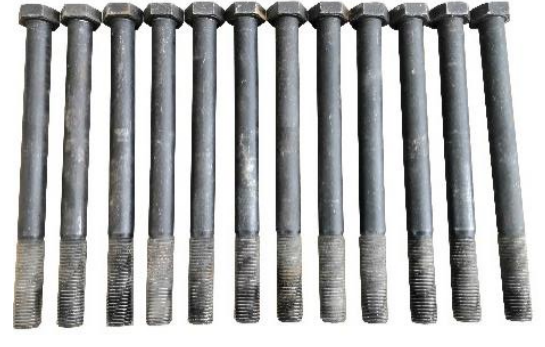

(c)

Fig. 7. Distortions of the components of the frame except EDPs. (a) a stub; (b) the joint part of EBP beam; (c) bolts

\subsubsection{Working mechanism analysis}

The hysteresis loop of the frame is presented in Fig. 8, where the displacement is obtained from the D1 and force from the actuator. The envelop profile is obtained from the first load cycle for each loading grade. The hysteresis loops is full without obvious pinching, indicating that the frame with EDP connections is of better energy dissipation performance.

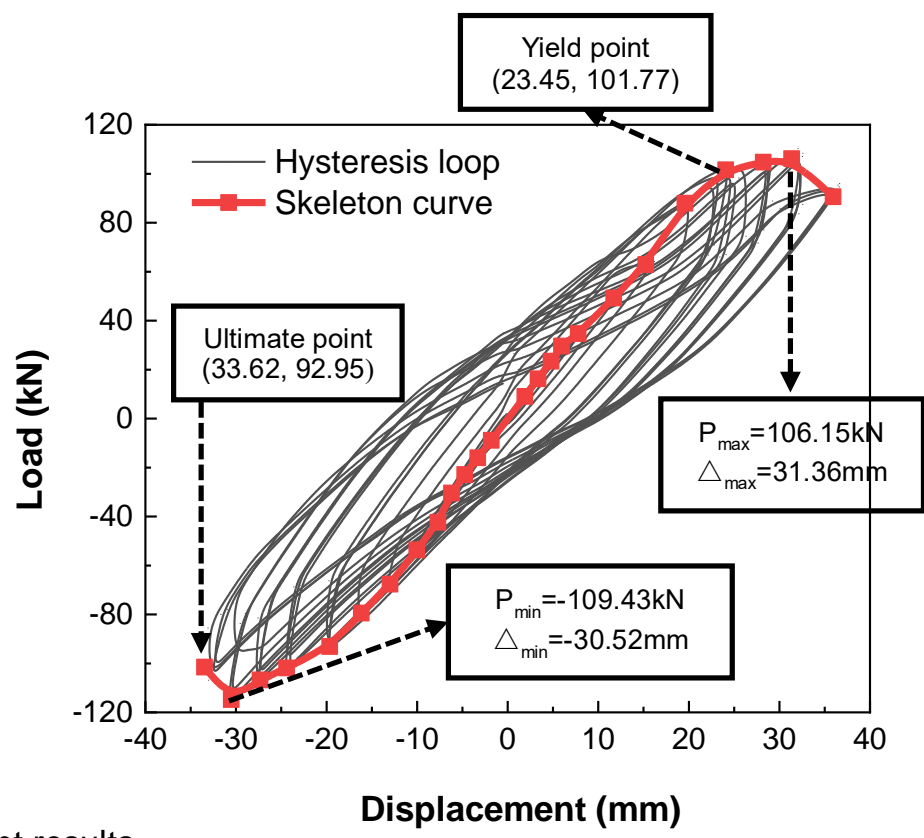

Fig. 8. Experiment results

The characteristics of the loop and the envelop profile can be summarized as follows: (1) At the beginning of loading, the response of the frame exhibited linear behavior, and the initial lateral stiffness were $4340 \mathrm{kN} / \mathrm{m}$; (2) As the external load exceeded 
the proportional limit, damage onset began on one or two of the EDPs, and the damage area continuously expanded with the load increasing, leading to continuous stiffness degradation till one of the EDP cracked. When the external load reaching its maximum value, the load-displacement profile went up to its summit point; (3) The load-displacement profile went down after passing through its summit till the other EDP cracked, the critical symbol of the failure of frame.

\section{Hysteretic Performances}

\section{Ductility and Damping Ratio}

The ductility ratio of the frame was estimated in terms of the Equivalent Energy Elastic-Plastic (EEEP) procedure addressed in ASTM E2126 (2010), as illustrated in Fig. 9. The yield point was determined by equating the area under the bi-linear EEEP response to the area under the test envelope curve, referring to Fig. 10. The ductility ratio is expressed as $\mu=\Delta_{\mathrm{u}} / \Delta_{\mathrm{y}}$, where, $\Delta_{\mathrm{y}}(\mathrm{mm})$ and $\Delta_{\mathrm{u}}(\mathrm{mm})$ are defined as yield and ultimate displacement, respectively. For the envelope with post-peak declining branch, $\Delta_{u}(\mathrm{~mm})$ is the displacement corresponding to the $0.8 \times$ maximum load.

The initial lateral stiffness of the frame is defined as stiffness before the first yielding takes place; hence it can be estimated by $K_{\text {initial }}=P_{\mathrm{y}} / 4$, where, $P_{\mathrm{y}}(\mathrm{kN})$ is the yield load. The energy dissipation of the frame is measured by the area of hysteresis loop. The damping ratio stands for the ratio of energy dissipated in one loop to the total strain energy in one loading-unloading cycle, and it can be calculated by $\varsigma=\frac{1}{2 \pi} \frac{S_{\text {Loop }}}{S_{\triangle O D E}+S_{\triangle O A F}}$. In this expression, $S(\mathrm{kN} \cdot \mathrm{m})$ represents area, and the subscripts, $\Delta_{\mathrm{ODE}}$ and $\Delta_{\mathrm{OAF}}$, stand for the triangles ODE and OAF, respectively, referring to Fig. 10. In this way, the damping ratio of the can be obtained, which is $14.1 \%$.

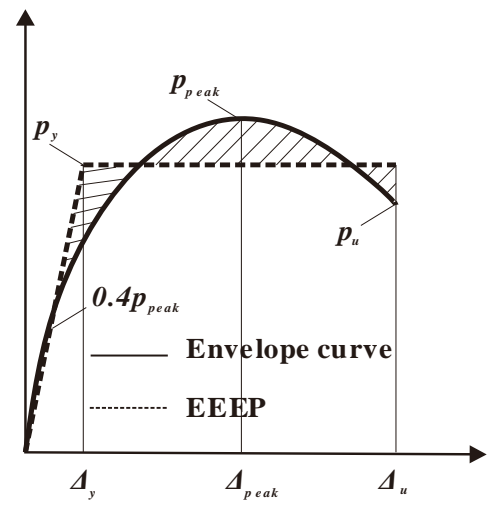

Fig. 9. Ductility ratio

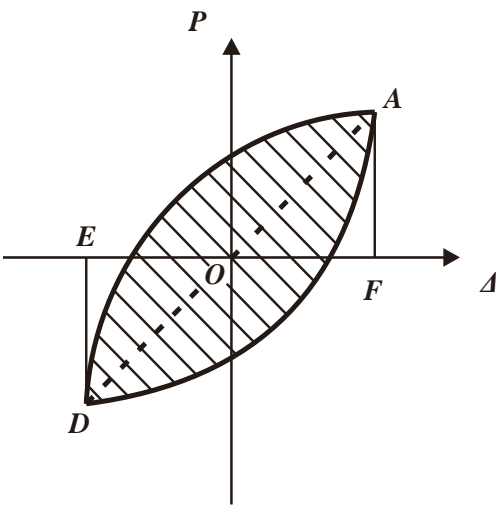

Fig. 10. Damping ratio

The values of yield load and associated displacement, ultimate load and associated displacement, initial stiffness, and ductility of the frame are presented in Table 3.

Table 3. Hysteretic Characteristics of the Experiment

\begin{tabular}{|c|c|c|c|c|c|c|}
\hline $\begin{array}{c}\text { Yield } \\
\text { load/kN }\end{array}$ & $\begin{array}{c}\text { Yield } \\
\text { displacement/ } \\
\mathrm{mm}\end{array}$ & $\begin{array}{c}\text { Ultimate } \\
\text { load/kN }\end{array}$ & $\begin{array}{c}\text { Ultimate } \\
\text { displacement// } \\
\mathrm{mm}\end{array}$ & $\begin{array}{c}\text { Initial } \\
\text { stiffness/ } \\
(\mathrm{kN} / \mathrm{m})\end{array}$ & $\begin{array}{c}\text { Ductility } \\
\text { ratio }\end{array}$ & $\begin{array}{c}\text { Damping } \\
\text { ratio }\end{array}$ \\
\hline 101.77 & 23.45 & 95.60 & 34.20 & 4340 & 1.46 & $14.1 \%$ \\
\hline
\end{tabular}




\section{Energy dissipation capacity}

The energy dissipation capacity is also an important aspect to make out the working mechanism and evaluate the seismic behavior of the hybrid frame. The energy dissipated by a single loop is calculated by $E_{j}=S_{\text {loop }}=\int P d \Delta$, where $\Delta(\mathrm{mm})$ represents the displacement. And the accumulate energy is the sum of every single loop, $E_{\text {accumulated }, j}=\sum_{i=1}^{j} E_{\text {loop }, \mathrm{i}} / \mathrm{E}_{\text {sum }}$, where $E_{\text {loop }, i}$ is the energy of $\mathrm{i}_{\text {th }}$ loop, and $\mathrm{E}_{\text {sum }}$ is the sum energy of all hysteresis loops in the test.

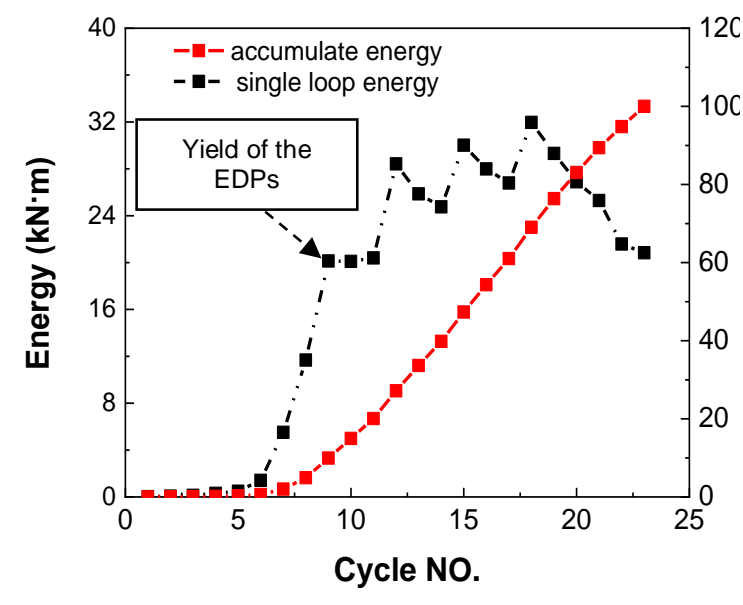

Fig. 11. Energy ratio

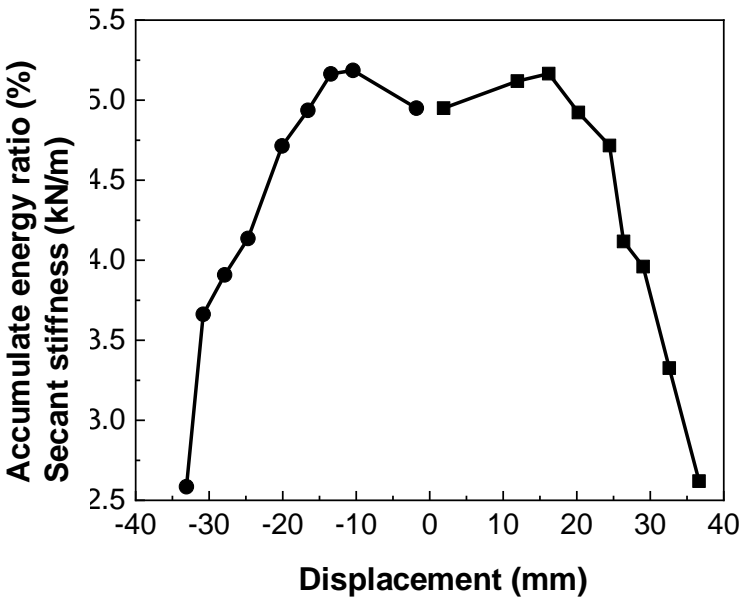

Fig. 12. Secant stiffness

The energy dissipation of a single loop and all loops is illustrated in Fig. 11. The following observations can be reached:

(1) Before the first yielding, the areas of the dissipated energy increase with the displacement. And the accumulated energy ratio is very small, indicating that the whole frame is working in elastic stage.

(2) When the lateral displacement reaches the yield of the EDPs, the energy dissipated by a single loop at the same displacement turn out to be different, i.e. the first loop is of the maximum area, while the other two loops keeps decreasing with the cyclic NO. increases.

(3) The accumulate energy of the frame increases with the increment of loading displacement. The maximum rate of increase occurs in where the yield displacement reaches.

\section{Secant stiffness}

Secant stiffness reflects the accumulation of structural damage, which is an important of the seismic performance of the structure. The secant stiffness $K_{i}$ of the specimen is defined as the slope of the hysteresis loop diagonal, which is expressed as $K_{i}=\frac{\left|+P_{i}\right|+\left|-P_{i}\right|}{\left|+\Delta_{i}\right|+\left|-4_{i}\right|}$, where $4,4, P_{i}$, and $P_{i}$ represents the maximum displacement (mm) and load (kN) of $i_{\text {th }}$ and $j_{t h}$ hysteresis loop, respectively.

Figure 12 shows the secant stiffness of the different displacement grades. Considering the results in Fig. 8, it can be concluded that the maximum stiffness degradation concentrates on the failure or cracking of the two EDPs. 


\section{Summary of Experimental Findings}

A full scale one-story one-bay engineered bamboo-steel hybrid frame with the novel energy-dissipation connections was conducted. The results can be conclude as follows:

(1) By a proper design, the damage and failure, including their position and mode in the hybrid frame, can be restricted to EDPs, which is identical to those of connection tests and design;

(2) The ductility and damping ratio of the engineered bamboo-steel frame can reach 1.46 and $14.1 \%$, respectively.

(3) The frame exhibit extra capacity of energy dissipation and ductility while the columns and beam remains in elastic range.

\section{FEM IMPLEMENTATION OF THE ENGINEERED BAMBOO-STEEL FRAME}

Finite Element Method (FEM) in ABAQUS (Dassault Systemes, Paris, France) was utilized to obtain numerical simulation of the engineered bamboo-steel frame under cyclic loading (Zhou et al. 2007; Pachoumis et al. 2010; Oudjene et al. 2017; Zhou et al. 2019). The comparison of the test and the first finite element model was used to verify the effectiveness of FEM analysis. After that, other FEM models with changed parameters were constructed to study the influences of these factors on the performance of the hybrid frame.

Detailed information of the energy dissipation joint, steel columns, and engineered bamboo beam were the same as those in Fig. 2. As aforementioned, the stress of the steel columns and engineered bamboo beams were monitored to ensure them working within elastic range in the test. Thus, only the elastic modulus of the steel column and engineered bamboo beam in Table 2 were adopted to define their orthogonal characteristics in linear elastic stage. While the behavior of EDPs turn out to be in the range of elastic-plastic, so the whole life stage, i.e. elastic stage, softening stage and strengthening stage, should be included in the strain-stress relation. Figures 13 and 14 show the simplified stress and strain relations of wood and two different kinds of steel from the material tests, respectively. Equations 3 and 4 show the transformation from nominal to real strain-stress relationship, where $\varepsilon_{y}$ and $\sigma_{y}$ represents the yield strain and stress, $\varepsilon_{p}$ and $\sigma_{p}$ for the post-yield, $\varepsilon_{u}$ and $\sigma_{u}$ for the ultimate strain and stress Besides, non-negligible damage of the EDPs was observed in the process of cyclic loading; thus the damage criteria of ductile in ABAQUS (Dassault Systemes, Paris, France) was chosen to simulate the evolution of material damage, as presented in Fig. 15. And the established FE model and its corresponding mesh are shown in Fig. 16.

The transformation of real and nominal strain-stress relationship of the steel can be explained as follows,

$$
\begin{aligned}
& \sigma_{\text {real }}=\sigma_{\text {nom }}\left(1+\varepsilon_{\text {nom }}\right) \\
& \varepsilon_{\text {real }}=\int_{l_{0}}^{l} \frac{d l}{l}=\ln \frac{l}{l_{0}}=\ln \left(1+\varepsilon_{\text {nom }}\right)
\end{aligned}
$$

where $\sigma_{\text {nom }}, \sigma_{\text {real }}, \varepsilon_{\text {nom }}$ and $\varepsilon_{\text {real }}$ represent nominal and real strain $(\mu \varepsilon)$-stress (MPa), respectively. 
Table 4. Transformation of Nominal and Real Strain and Stress of the Steel

\begin{tabular}{|c|c|c|c|c|c|}
\hline & $\begin{array}{c}\text { Nominal } \\
\text { stress } / \mathrm{MPa}\end{array}$ & $\begin{array}{c}\text { Nominal } \\
\text { strain }\end{array}$ & $\begin{array}{c}\text { Real stress } \\
/ \mathrm{MPa}\end{array}$ & Real strain & Plastic strain \\
\hline Yield point & 314 & 0.0015 & 314.5 & 0.0015 & 0 \\
\hline $\begin{array}{c}\text { Post-yield } \\
\text { point }\end{array}$ & 315 & 0.003 & 315.9 & 0.003 & 0.0015 \\
\hline Ultimate point & 445 & 0.4 & 580 & 0.34 & 0.337 \\
\hline & - & - & 600 & - & 2 \\
\hline
\end{tabular}

NOTE: The last row of real strain and stress are only used to ensure the final plastic stress is great enough and the stress-strain relationship keeps increasing in ABAQUS. It has no actual meaning.

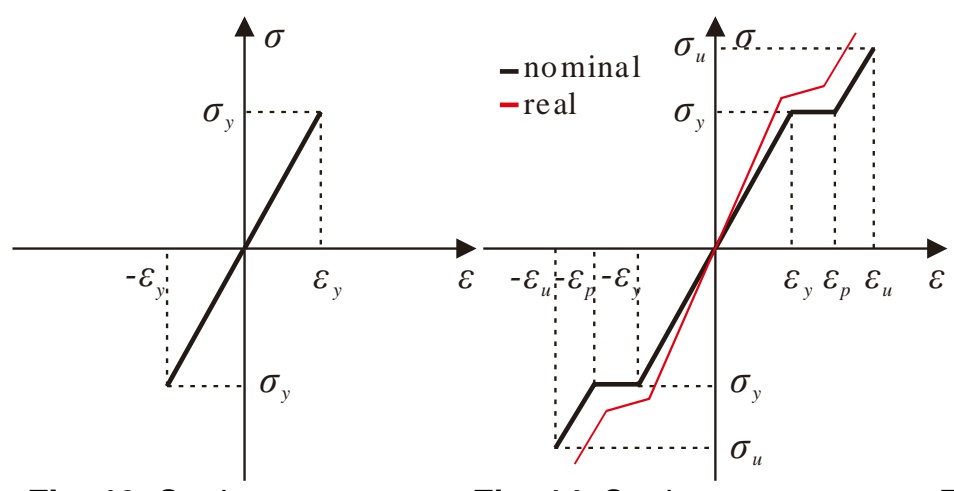

Fig. 13. Strain-stress relationship of steel column and bamboo beam
Fig. 14. Strain-stress relationship of EDP

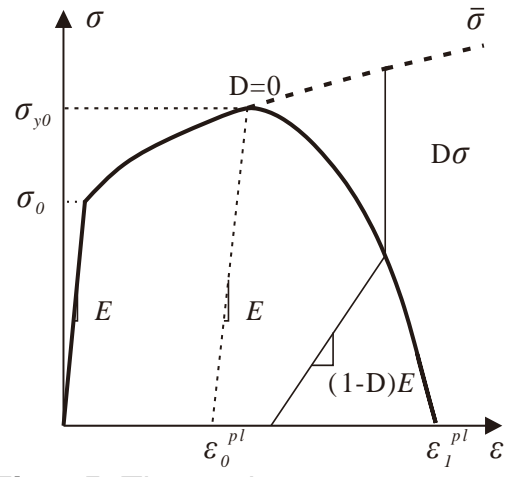

Fig. 15. The strain-stress relationship of damage degradation model

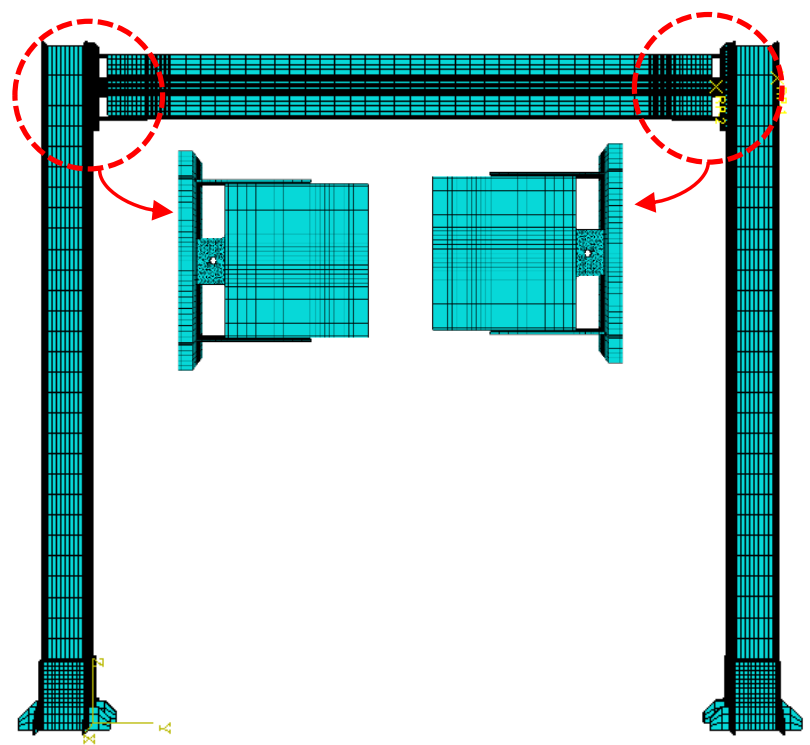

Fig. 16. FEM model and mesh of the engineered bamboo-steel composite frame

The element type of C3D8R (three-dimensional eight-node linear brick elements with reduced integration) in ABAQUS was chosen to simulate the large deformation of EDPs, while the other components adopted C3D20R (three-dimensional twenty-node linear brick elements with reduced integration). The horizontal load or displacement was 
applied on a reference point (the middle point of the load area in the simulation) coupling a surface divided on the column, whose area equals to the contacting surface of the actuator. Only U1 (the horizontal displacement) was constrained with the reference point to exert the same lateral displacement regime in Fig. 3 was adopted.

It is worth noting that the contacts are one of the most major concerns of convergence and computing efficiency in FEM. To simplify the FE model and enhance the computing efficiency, the connections between beam, column, and the energy dissipation joint were set as "tie" (a kind of constraint) in the ABAQUS model, indicating the rigid connections of them. The bolts in the hinge bear the shear of the joint, the connections there cannot be neglected. Therefore, the contact type "hard contact" is used to define the relationship between them with regardless of the friction of the contact surfaces. The bottom surfaces of two columns are fixed on the laboratory ground.

In order to demonstrate the whole mechanical process of the joint under cyclic loading, the analysis step "Dynamic Explicit" was selected to simulate the element distortion and failure of energy dissipation plate. Compared with "Static General" (a kind of implicit analysis steps), it is of the advantages, such as the ability to deal with complex contact and convergence problems, better simulation of stiffness degradation of failure element and the feasibility to predict its computing time. The simulation of cyclic loading in "Dynamic Explicit" is a kind of quasi-static problem in essence, the displacement loading time should be identical with the actual test. Besides that, the mass scaling factor was set as 10000 to accelerate the analysis procedure without influences on the calculated precision.

\section{SIMULATION RESULTS AND DISCUSSION}

Using the FEM model above, the seismic behaviors and failure mode of engineered bamboo-steel composite frame were compared with those in cyclic loading test. The deformation, stress distribution, hysteresis performance, and ductility ratio of the frame were studied.

\section{Deformation and Stress Distribution}

The stress and deformation of the energy-dissipation connection and the steel column at the maximum displacement are shown in the following two figures. A Von Mises stress nephogram is applied to show the stress distribution.

As shown in Fig. 17, the maximum stress or strain occurs mainly in the EDPs. Three working stages can be divided through the deformation and stress distribution. For stage I, there is no obvious deformation that can be observed, and each component is within the elastic working range. Stage II, the EDPs begin to buckle after the middle section reaches its yield stress, and the buckling keeps increasing with the increase of lateral load. Stage III, failure and element deletion occur when the strain in the middle of the EDPs exceeds its strain limits. When the displacement exerted on the frame is great enough, the EDPs crack in the middle after fully bucking. 

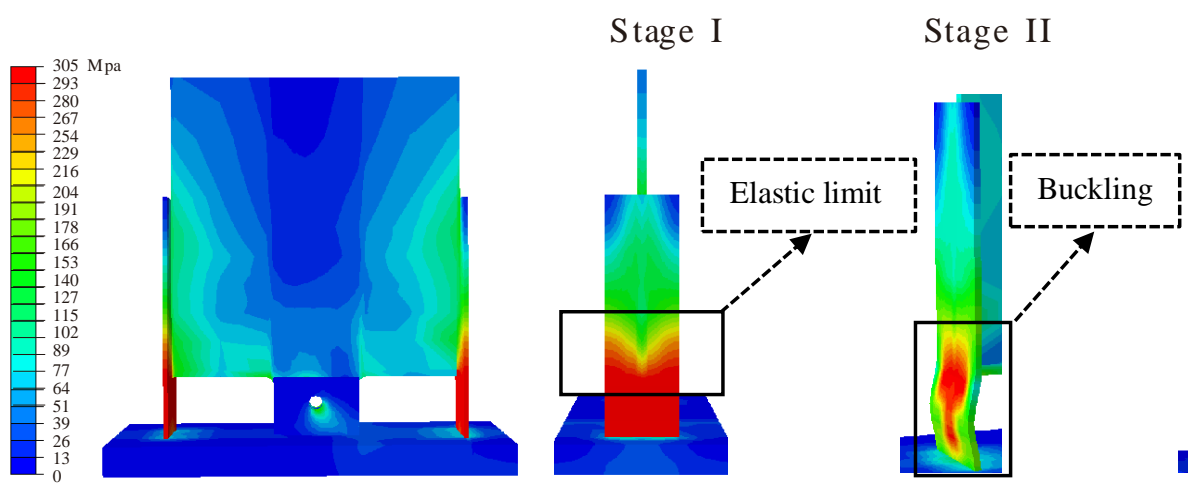

Stage III

Fig. 17. Stress nephogram of the energy dissipation connections

The three working stages correspond well with the design aims and failure mode of the cyclic test. And during the cyclic displacement loading, the EDPs reach their elastic limits and begin to buckle, which is exactly the same as that in cyclic loading tests of engineered bamboo-steel composite and energy dissipation joint.

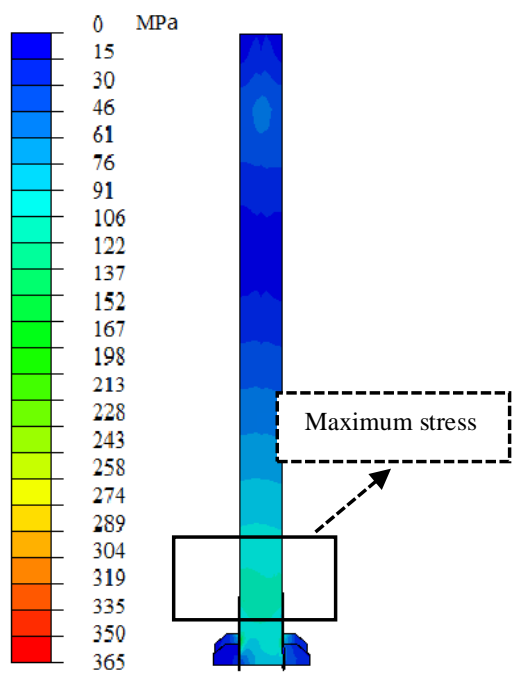

(a)

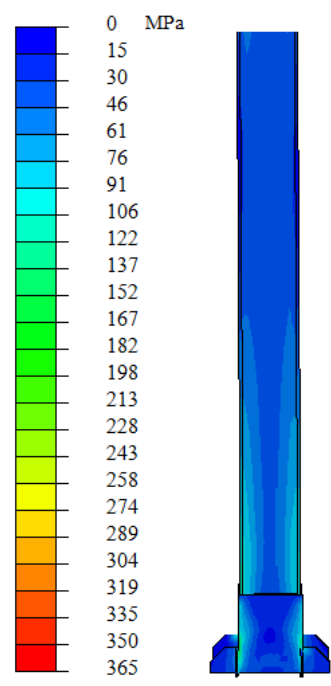

(b)

Fig. 18. Stress nephogram of the column and bolt; (a) front view; (b) lateral view

Figure 18 presents the stress distribution of vertical components in the engineered bamboo-steel hybrid frame. The maximum stress occurs in the place where the cross section changes, which is identical with the monitored test results. And the Von Mises stress of the whole frame revealed that the vertical components are in elastic range without any damage. The deformation and stress distribution of the simulation correspond well with those of experimental results, preliminary verifying the effectiveness of the finite element model.

\section{Skeleton Curve}

The comparison between the skeleton curve is presented in Fig. 19. It can be observed that the shapes of skeleton curve are basically of the identical shape. When the 
buckling occurs in the middle of EDPs, the stiffness of the composite frame begins degrading till the EDPs crack.

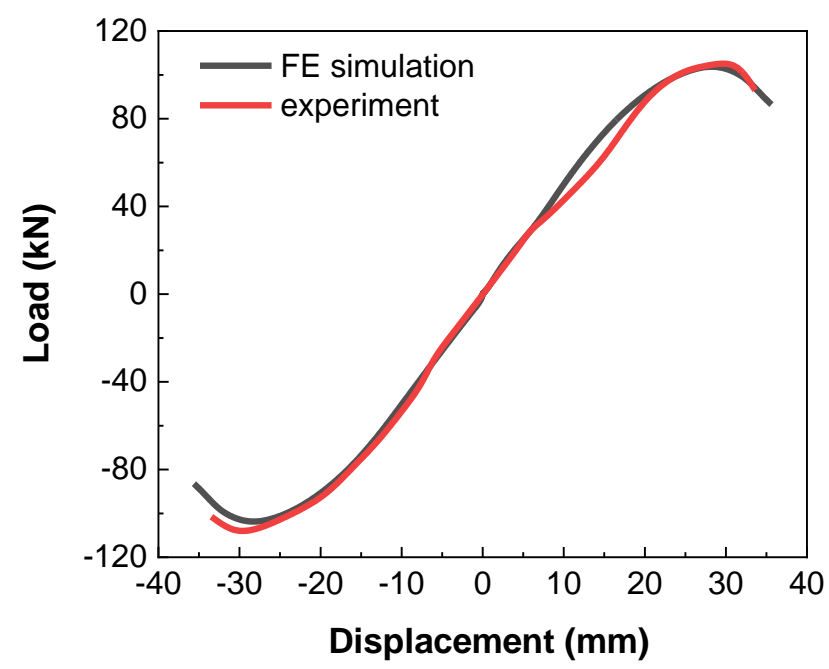

Fig. 19. The comparison of skeleton curves between FEM simulation and test

Differences in the middle working stage between the experiment and simulation skeleton curves can be found, indicating that the stiffness of the frame in FEM simulation is larger than that in actual test. There are mainly two reasons can be used to explain the phenomenon: (1) the limits of finite element method, i.e., there is no extrusion and embedding between solid elements, is a concern that leads to the greater initial stiffness; (2) there are some small sliding or gaps between experiment setups, which are systematic errors and inevitable. It is notable that the skeleton curves between FE simulation and tests are in good agreement in the nest process when the displacement is greater than $15 \mathrm{~mm}$. This can be explained by reason that the displacement is great enough to offset the gaps or small sliding, and the latter reason above should be the major concern that leads to the errors between experiment and simulation. The fact that the overall error except for the initial stage is less than $5 \%$, while the initial stage is less than $15 \%$, can serve as another support for the conclusion above.

Combined with the analysis and comparison, the FE simulation of the composite frame can be regarded as a reliable method to explore its mechanical and seismic performances.

\section{Influence of EDP Size on Damping and Ductility Ratios}

Another four groups of engineered bamboo-steel hybrid frame with different sized novel energy dissipation connections were simulated by FE simulation in ABAQUS. According to the design disciplines in reference (Huang et al. 2019), the length-to-depth ratio should be in the range of 6.6 to 16, and only the depth of EDPs changed with other components remain identical with the composite frame experiments. Since the skeleton curves are symmetric on the origin point, only the positive part of the skeleton curves is shown in Fig. 20. Table 5 shows the ductility ratios of expanded simulation in ABAQUS. The same analysis methods in part 2 are used for calculations of ductility ratio of the frames. 


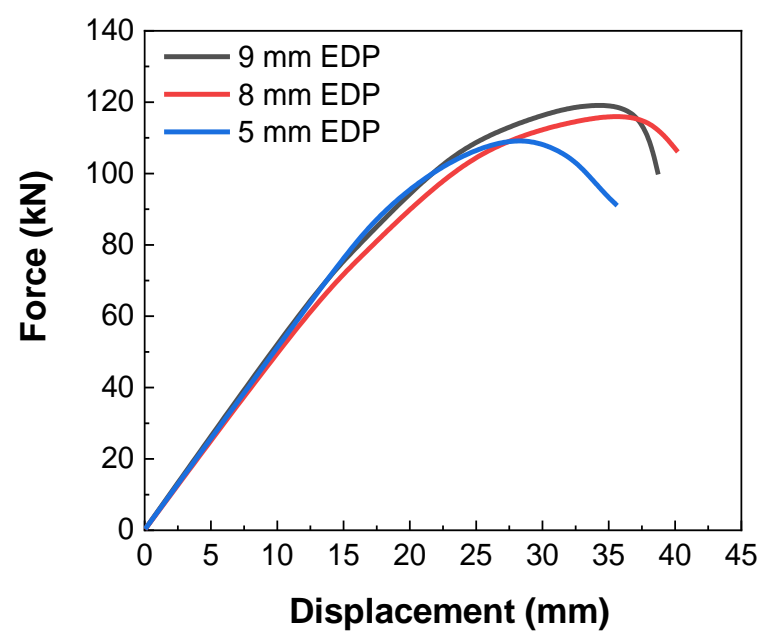

Fig. 20. The skeleton curves of hybrid frame with different sized EDPs

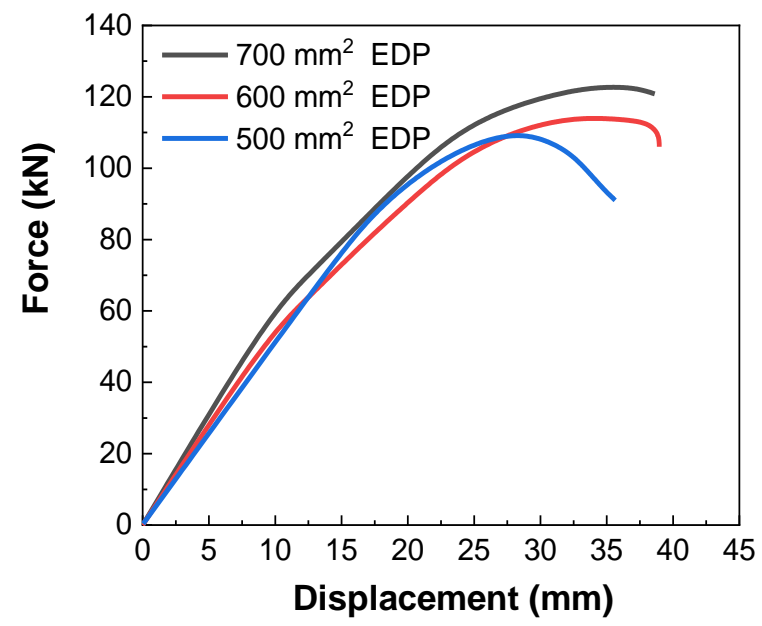

Fig. 21. The skeleton curves of hybrid frame with EDPs of different cross sections

Table. 5. Seismic Performance of Different Sized Energy Dissipation Joint Frame

\begin{tabular}{|c|c|c|c|c|c|c|}
\hline $\begin{array}{c}\text { Group } \\
\text { NO. }\end{array}$ & $\begin{array}{c}\text { Depth of } \\
\text { EDP } / \mathrm{mm}\end{array}$ & $\begin{array}{c}\text { Length-to- } \\
\text { depth ratio } \\
(\mu)\end{array}$ & $\begin{array}{c}\text { Cross section of } \\
\text { the EDPs/mm2 }\end{array}$ & $\begin{array}{c}\text { Ductility } \\
\text { ratio }\end{array}$ & $\begin{array}{c}\text { Peak } \\
\text { load/kN }\end{array}$ & $\begin{array}{l}\text { Initial } \\
\text { stiffness } \\
\text { /kN } \cdot \mathrm{mm}^{-} \\
1\end{array}$ \\
\hline I & 5 & 14 & 500 & 1.77 & 107.19 & 4.81 \\
\hline II & 8 & 8.75 & 500 & 1.87 & 116.53 & 4.62 \\
\hline III & 10 & 7 & 500 & 1.85 & 119.46 & 4.70 \\
\hline IV & 6 & 11.67 & 600 & 1.81 & 114.03 & 5.18 \\
\hline V & 7 & 10 & 700 & 1.84 & 122.85 & 6.07 \\
\hline
\end{tabular}

It can be observed that the skeleton curves of the three hybrid frames are of similar shape and working stages, which is exactly the same with the hybrid experiment: Stage I, the displacement-force curve turns out to be a straight line with a constant slope, indicating all components working in elastic range; Stage II, when the stress of EDPs reaches their elastic limits and begins to buckle, the displacement-force curve goes through a stage with decreasing stiffness until reaching their peak loads. After that, the stress keeps increasing 
to the critical value with the increase of external load till element distortion and deletion occurs. There will be a negative stiffness segment in the displacement-load curve. The seismic parameters, i.e., ductility, peak load and initial stiffness of the simulation in ABAQUS are shown in the following table.

The following observation can be made based on the simulation results of the steelengineered bamboo hybrid frame:

(1) The initial stiffness of the hybrid frame is directly related to the cross section of the EDPs;

(2) When the cross section remain as a constant, the peak load keeps increasing with the increase of the depth or cross section of EDPs, which indicates that the depth or the length-to-depth ratio is of great importance to peak load of engineered bamboo-steel hybrid frame.

(3) The ductility ratio of the different sized hybrid frame is determined by both the length-to-depth ratio and the cross section. If the cross section remain as a constant, the ductility will reach its maximum when proper length-to-depth ratio is adopted. In this simulation, the most proper length-to-depth ratio is 8.75 .

\section{CONCLUSIONS}

Cyclic loading test and finite element simulation on a full-scale one-story one-bay engineered bamboo-steel hybrid frames with the novel energy-dissipation connections were conducted to investigate its hysteretic performance. The test result showed that the damage and failure can be restricted to the local buckling of energy-dissipation panels (EDPs), which was identical to those of connection tests and design aims. And the hybrid frame with the novel energy-dissipation connections exhibited excellent hysteretic characteristics, with the ductility and damping ratio of the engineered bamboo-steel frame reaching 1.46 and $14.1 \%$, respectively

Besides that, FE simulations in ABAQUS with different parameters were analyzed and compared to explore the influences of length-to-depth ratio and cross section of EDPs on the ductility, damping ratio, load-carrying capacity and initial stiffness of the hybrid frame. The major conclusions can be achieved as follows:

The initial stiffness of the hybrid frame is merely related to the cross sections and materials of EDPs, while the peak lateral force and the ductility (or the load-carrying capacity) of the hybrid frame is determined by both the cross section and length-to-depth ratio of the EDPs. The recommended length-to-depth ratio is 8.75.

\section{ACKNOWLEDGMENTS}

The study was supported by National Intensive Research Project, 2017YFC0703500 and the National Natural Science Foundation of China, 6505000184. Their supports are gratefully acknowledged. 


\section{REFERENCES CITED}

Adi, M. N., Drew, R., Al-Hussein, M., Embury-Williams, L. and Karacabey, E. (2015). Application of Analysis Tools from NEWBuildS Research Network in Design of a High-Rise Wood Building, NEWBuildS, Fredericton, NB, Canada, pp. 5-12.

Araki, Y., Endo, T., and Iwata, M. (2011). "Feasibility of improved slotted bolted connection for timber moment frames," Journal of Wood Science 57(3), 247-253. DOI: $10.1007 / \mathrm{s} 10086-010-1165-7$

ASTM E2126-11 (2010). "Standard test methods for cyclic (reversed) load test for shear resistance of vertical elements of the lateral force resisting systems for buildings," ASTM International, West Conshohocken, PA.

Bouchaïr, A., Racher, P., and Bocquet, J. F. (2007). "Analysis of dowelled timber to timber moment-resisting joints," Materials and Structures 40(10), 1127-1141. DOI: 10.1617/s11527-006-9210-0

Buchanan, A., Deam, B., Fragiacomo, M., Pampanin, S., and Palermo, A. (2008). "Multistorey prestressed timber buildings in New Zealand," Structural Engineering International 18(2), 166-173. DOI: 10.2749/101686608784218635

GB50017-2017. (2017) "Standard for design of steel structures," Standardization Administration of China, Beijing, China.

He, M., Li, Z., Lam, F., Ma, R., and Ma, Z. (2013). "Experimental investigation on lateral performance of timber-steel hybrid shear wall systems," Journal of Structural Engineering, 140(6), 04014029. DOI: 10.1061/(ASCE)ST.1943-541X.0000855

Huang, D., Bian, Y., Zhou, A., and Sheng, B. (2015). "Experimental study on stressstrain relationships and failure mechanisms of parallel strand bamboo made from Phyllostachys," Construction and Building Materials, 77, 130-138. DOI: 10.1016/j.conbuildmat.2014.12.012

Huang, D., Zhou, A., and Bian, Y. (2013). "Experimental and analytical study on the nonlinear bending of parallel strand bamboo beams," Construction and Building Materials 44, 585-592. DOI: 10.1016/j.conbuildmat.2013.03.050

Huang, Z., Chen, Z., Huang, D., and Chui, Y. H. (2019). "Cyclic loading behavior of an innovative semi-rigid connection for engineered bamboo-steel hybrid frames," Journal of Building Engineering 24, 100754. DOI: 10.1016/j.jobe.2019.100754

Huang, Z., Chen, Z., Huang, D., and Zhou, A. (2016). "The ultimate load-carrying capacity and deformation of laminated bamboo hollow decks: Experimental investigation and inelastic analysis," Construction and Building Materials 117, 190197. DOI: 10.1016/j.conbuildmat.2016.04.115

Hurmekoski, E., Jonsson, R., and Nord, T. (2015). "Context, drivers, and future potential for wood-frame multi-story construction in Europe," Technological Forecasting and Social Change 99, 181-196. DOI: 10.1016/j.techfore.2015.07.002

Kharouf, N., McClure, G., and Smith, I. (2003). "Elasto-plastic modeling of wood bolted connections," Computers \& Structures 81(8-11), 747-754. DOI: 10.1016/S00457949(02)00482-0

Li, Z., He, M., Ma, Z., Wang, K., and Ma, R. (2016). "In-plane behavior of timber-steel hybrid floor diaphragms: experimental testing and numerical simulation," Journal of Structural Engineering, 142(12), 04016119. DOI: 10.1061/(ASCE)ST.1943541X.0001601 
Li, Z., He, M., and Wang, K. (2018). "Hysteretic performance of self-centering glulam beam-to-column connections," Journal of Structural Engineering 144(5), 04018031. DOI:10.1061/(ASCE)ST.1943-541X.0002012

Loss, C., Piazza, M., and Zandonini, R. (2016). "Connections for steel-timber hybrid prefabricated buildings. Part I: Experimental tests," Construction and Building Materials 122, 781-795. DOI: 10.1016/j.conbuildmat.2015.12.002

Mohammad, M., and Quenneville, J. H. (2001). "Bolted wood steel and wood steel wood connections: Verification of a new design approach," Canadian Journal of Civil Engineering 28(2), 254-263. DOI: 10.1139/100-105

Oudjene, M., Tran, V. D., and Khelifa, M. (2017). "Cyclic and monotonic responses of double shear single dowelled timber connections made of hardwood species: Experimental investigations," Construction and Building Materials 132, 188-195. DOI: 10.1016/j.conbuildmat.2016.11.127

Pachoumis, D. T., Galoussis, E. G., Kalfas, C. N., and Efthimiou, I. Z. (2010). "Cyclic performance of steel moment-resisting connections with reduced beam sectionsexperimental analysis and finite element model simulation," Engineering Structures, 32(9), 2683-2692. DOI: 10.1016/j.engstruct.2010.04.038

Porteous, J., and Kermani, A. (2013). Structural Timber Design to Eurocode 5, John Wiley \& Sons, New York, NY, USA.

Quenneville, J. H., and Mohammad, M. (2001). "Design method for bolted connections loaded perpendicular-to-grain," Canadian Journal of Civil Engineering 28(6), 949959. DOI: $10.1139 / 101-059$

Sakamoto, I., Kawai, N., Okada, H., Yamaguchi, N., Isoda, H., and Yusa, S. (2004). "Final report of a research and development project on timber-based hybrid building structures," in: Proceedings of $8^{\text {th }}$ World Conference on Timber Engineering, June (Vol. 2, pp. 53-64).

Santos, C. L., de Jesus, A. M., Morais, J. J., and Fontoura, B. F. (2013). “An experimental comparison of strengthening solutions for dowel-type wood connections," Construction and Building Materials 46, 114-127. DOI: 10.1016/j.conbuildmat.2013.03.021

Schoenwald, S., and Hu, L. (2014). Technical Guide for the Design and Construction of Tall Wood Buildings in Canada, FP Innovations, Quebec, Canada.

Sharma, B., Gatóo, A., Bock, M., and Ramage, M. (2015). "Engineered bamboo for structural applications," Construction and Building Materials 81, 66-73. DOI: 10.1016/j.conbuildmat.2015.01.077

Shiratori, T., Leijten, A. J. M., and Komatsu, K. (2009). "The structural behaviour of a pre-stressed column-beam connection as an alternative to the traditional timber joint system," Engineering Structures 31(11), 2526-2533. DOI:

10.1016/j.engstruct.2009.05.003

Schober, K. U., and Tannert, T. (2016). "Hybrid connections for timber structures," European Journal of Wood and Wood Products 74(3), 369-377. DOI: 10.1007/s00107-016-1024-3

Van der Lugt, P., Van den Dobbelsteen, A. A. J. F., and Janssen, J. J. A. (2006). “An environmental, economic and practical assessment of bamboo as a building material for supporting structures," Construction and building materials 20(9), 648-656. DOI: 10.1016/j.conbuildmat.2005.02.023

Williams, L. E., and Karacabey, E. (2014). "Application of analysis tools from NEWBuilds research network in design of high-rise wood buildings," NSERC 
Strategic Research Network on Innovation Wood Products and Building Systems (NEWBuilds), Canada.

Xiong, H., Liu, Y., Yao, Y., and Li, B. (2016). "Experimental study of reinforcement methods and lateral resistance of glued-laminated timber post and beam structures," Journal of Tongji University (Natural science) 44(5), 695-702. DOI: 10.11908/j.issn.0253-374x.2016.05.006

Zhou, F., Mosalam, K. M., and Nakashima, M. (2007). "Finite-element analysis of a composite frame under large lateral cyclic loading," Journal of Structural

Engineering, 133(7), 1018-1026. DOI: 10.1061/(ASCE)0733-9445(2007)133:7(1018)

Zhou, L., Chui, Y. H., and Ni, C. (2019). "Numerical study on seismic force modification factors of hybrid light wood frame structures connected to a stiff core," Engineering Structures 183, 874-882. DOI: 10.1016/j.engstruct.2019.01.082

Article submitted: October 8, 2019; Peer review completed: February 22, 2020; Revised version received: March 21, 2020; Accepted: March 22, 2020; Published: March 30, 2020.

DOI: $10.15376 /$ biores. $15.2 .3504-3523$ 